\title{
CHANGING THERMAL COMFORT OVER SOUTHERN INDIA UNDER WARMING ENVIRONMENT: AN ANALYSIS OF HEAT INDEX
}

\author{
Manasi DESAI ${ }^{1}$, A. G. DHORDE ${ }^{2}$
}

\begin{abstract}
Changing thermal comfort over southern India under warming environment: an analysis of heat index. In the present study, trends in Heat Index were analyzed to assess heat stress conditions at 41 urban stations of southern peninsular India during monsoon season months (June to September) for the period 1969-2014. Results indicated that, with the exception of insignificant decrease at few stations, almost all stations registered significant increase in heat stress. Change point detection depicted that, increase in heat stress initiated in late 1990's and early years of the decade of 2000 at most of the urban stations. Hierarchical cluster analysis partitioned data in seven spatial units. Accordingly highest magnitude of increase was observed over cities located in northeast part of the study area, followed by cities located at southern tip of peninsular India. The study demands attention on precarious health risks inscriptive to increasing heat stress casualties and developing indigenous thermal stress alerts during persistent climate extremes.
\end{abstract}

Keywords: heat index, trend, urban stations, cluster analysis, India

\section{INTRODUCTION:}

Globally there has been increase in the frequency of daily temperature extremes. Observed warming over several decades has been linked to changes in the large scale hydrological cycle such as increase in atmospheric water vapor content (IPCC 2008). The population of South Asia is highly vulnerable to heat related mortality; risk further magnifies due to high rate of urbanization and lack of efficient adaptation strategies (Stocker et al. 2013). Kleerekoper et al. (2012) indicate that global temperature rise combined with microclimatic effect like Urban Heat Island (UHI) may result into unhealthy heat stress and even significant increase in heat related mortality. The urban microclimate created by modifications in urban landscape (Arnfield 2003) along with attenuated meteorological parameters has higher implications on human thermal comfort (Unger 1999). India, being a developing country and one of the fastest emerging economies of the world, is highly dependent on human resource and has large concentration of population in urban areas, dwelling on insufficient urban resources. A study by Smoyer et al. (2000)

\footnotetext{
${ }^{1}$ Department of Geography, Savitribai Phule Pune University (formerly University of Pune), Pune 411007, Maharashtra, India, email: desaimanasi02@gmail.com

2 Department of Geography, Savitribai Phule Pune University (formerly University of Pune), Pune 411007, Maharasthra, India, email: amitdhorde@unipune.ac.in, amitdhorde@gmail.com (corresponding author)
} 
highlights that, demographic characteristics and socio-economic factors threaten and impedes adaptive capacity of population to deal with heat stress adversities.

Heat Index was originally developed by Steadman (1979), as an assessment for sultriness. Steadman's indices assessed thermal comfort by using an iterative solution for multiple variables in multiple equations representing body's temperature and moisture transfer combining atmospheric air temperature and humidity. The equations were later modified and used as single approximated Heat Index (HI) equation by Rothfusz (Iheanacho 2014). Thus, the computation of the heat index is a refinement of a result obtained by multiple regression analysis carried out by Rothfusz and described in 1990 National Weather Service-National Oceanic and Atmospheric Administration (NWS-NOAA), United States of America (USA) Technical Attachment (SR 90-23) (Rothfusz and Headquarters 1990).

In the present study, $\mathrm{HI}$ is used by applying necessary adjustments as described by NWS-NOAA (http://www.wpc.ncep.noaa.gov/html/heatindex equation.shtml). $\mathrm{HI}$ is one of the most popular index for environmental health research as a measure of thermal comfort (Anderson et al. 2013). It is used for studies related to outdoor temperature exposures and development of synoptic scale heat warning systems (Brooke et al. 2013). The HI index was devised in USA and had been used to evaluate thermal stress conditions for USA (Robinson 2001, Glazer 2005). In India Mohan et al. (2014) with the application of HI, studied thermal comfort conditions of five metropolitan cities and provided relative ranking of the cities on the basis of thermal comfort experienced in each of the five cities.

In the present study attempt was made to analyze spatio-temporal trends in heat Index for 41 selected urban weather stations of southern India during south west monsoon season months (June to September).

\section{MATERIALS AND METHODS}

\subsection{Study area and data used}

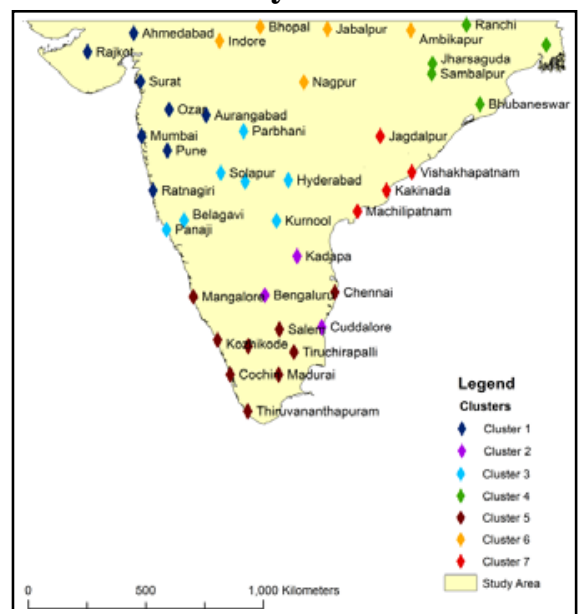

Fig. 1. Location of stations and clusters identified
The southern peninsular India is characterized by tropical wet and dry climate. Wet period is confined to southwest monsoon season (June to September) for majority of peninsular region, while eastern coastal region experience wet season during northeast monsoon season (October to December). The central part of Indian peninsular region receives meager rainfall and thus is subjected to hot and dry climate. Summer season is marked by scorching heat and commencement of monsoon leads to muggy, sultry weather conditions. Thus during monsoon season transition from hot summer to humid monsoon with intermittent breaks apparently builds heat stress pertaining 
to tropical hot temperature and high atmospheric humidity. Figure 1 illustrates the location of stations and the clusters identified.

\subsection{Temporal trend analysis}

Linear regression model was applied for temporal trend analysis. It has been widely used for several climatological studies for assessment of long term tendency in climatic parameters (Dash et al. 2007). Magnitude of trend was obtained from the slope (value of 'b') of the regression line. Significance of trends was checked by Student's t test at 95\% confidence level. Besides parametric test, non-parametric Mann Kendall (MK) rank test was applied to verify results of temporal trends. The test had been used by Gadgil and Dhorde (2005) and Zarenistanak et al. (2014) for temporal trend detection of meteorological time series. The magnitude of slope in time series data (1969-2015) was calculated also with Theil-Sen approach (TSA). TSA is considered more robust than the least-squares method due to its relative insensitivity to extreme values and better performance even for normally distributed data (Hirsch et al. 1982). TSA is a non-parametric method and is used to estimate the magnitude of trends in climatological and hydrological time series data (Ahmad et al. 2015, Chattopadhyay and Edwards 2016, Antonopoulos et al. 2001).

\subsection{Change point detection}

Sequential Mann Kendall (SQ-MK) is a method used to test an assumption about beginning of trend development within a sample. The test determines approximate year for the initiation of significant trend. The details of the test are explained in WMO technical note 123 (1990). In SQ-MK graphs upper and lower confidence limits were set up at +1.96 and -1.96 respectively. The test has been applied for change point detection in several meteorological and hydrological studies (Partal and Kahya 2006, Karpouzos et al. 2010).

\subsection{Cluster analysis}

Cluster analysis is one of the multivariate statistical techniques used for classification and segregation of observations based on their similarity and dissimilarity (Gong and Richman 1995). Cluster analysis therefore involves the groupings of similar entities or observations that exhibit two properties external isolation and internal cohesion (Cormack 1971). The hierarchical clustering algorithm creates a nested sequence of partitions of the patterns from dissimilarity matrix and proceeds through series of either successive mergers or successive divisions (Richette et al. 2013).

\section{ANALYSIS AND DISCUSSION}

\subsection{Cluster analysis and temporal trends}

Temporal trend analysis was carried out for average monthly HI values. Burst of monsoon gradually decreases scorching summer temperatures by $5^{\circ} \mathrm{C}$ to $6^{\circ} \mathrm{C}$ by mid July over most of the parts of the country. Southeastern region of India is an exception (parts of Tamilnadu and Andhra Pradesh), wherein decrease in temperature 
is not much prominent. Being a rain shadow region, temperatures are still high and increased moisture content of air may seldom result in rains. Moderately high tropical temperatures and frequent increase (decrease) of atmospheric moisture due to wet and dry spells characterize SW monsoon season. The 41 urban stations spread across southern peninsular India thus have distinct behavior during four months of SW monsoon. To segregate and create a combination a of stations which were having similar/dissimilar response during a season considered, the absolute change in heat index observed during each of the four months obtained through magnitude of change evaluated by slope value 'b' and TSA method along with locations of stations was used as a input for cluster analysis.

The Ward's method of cluster analysis separated and grouped 41 stations in seven different clusters, stations grouped together as a single cluster were experiencing complementary temporal trends distinct from other urban stations (Figure 1). Cluster 1 comprises of stations located in northwestern part of study area. Amongst 8 stations in this group HI values for 5 stations namely Ozar, Pune, Rajkot, Ratnagiri and Surat ranged between $-2^{\circ} \mathrm{C}$ to less than $2^{\circ} \mathrm{C}$, these stations either show decrease or meager increase in heat stress. Statistically significant increase was observed over Pune in August and September (Figure 2) and in the month of June at Rajkot, where temperatures still remain high as monsoon does not reach there by this time. Similar increase ranging between $1.3^{\circ} \mathrm{C}$ to $2^{\circ} \mathrm{C}$ was observed at Ahmedabad. Mumbai, a highly urbanized metropolitan city experienced significant increase in all four months except July. Highest absolute increase in heat stress was noticed during retreating monsoon months $\left(2^{\circ} \mathrm{C}\right.$ to $\left.2.5^{\circ} \mathrm{C}\right)$. Similarly, Aurangabad located in semi arid regime depicted significant increase in heat stress, highest absolute increase of this cluster was noted at this city in the month of June $\left(3.3^{\circ} \mathrm{C}\right)$. Cluster 2 is a smallest group (Figure 1), consisting of three cities Bengaluru, Cuddalore and Kadapa, though Bengaluru (August and September) and Cuddalore depicts significant increase in heat stress, the absolute increase at these stations was comparatively less. At Bengaluru $\mathrm{HI}$ varied between $0.2^{\circ} \mathrm{C}$ to $1^{\circ} \mathrm{C}$, while at Cuddalore range of $\mathrm{HI}$ was within $0.5^{\circ} \mathrm{C}$ to $2.5^{\circ} \mathrm{C}$. Kadapa depicted decreasing trend in heat stress, though significant in July and August, in accordance to robust TSA method change was insignificant (Figure 1).

The cities located over central India were grouped to form cluster 3 (Figure 1). Except Panaji and Belgaum, which experience tropical monsoon climate, other cities in this cluster experience semi-arid climatic conditions.

All cities in this cluster showed increasing trend in heat stress (Figure 2). Heat index values varied between $0.9^{\circ} \mathrm{C}$ to $3^{\circ} \mathrm{C}$ during June. In peak monsoon months, July and August absolute increase in heat stress was more than $1^{\circ} \mathrm{C}$ and reached $3^{\circ} \mathrm{C}$. Panaji experienced significant increase in all SW monsoon months, absolute increase at this station was more than $2^{\circ} \mathrm{C}$ during all the four monsoon months. Panaji was followed by Parbhani depicting similar pattern, increase at this station ranged between $1.2^{\circ} \mathrm{C}$ to $3^{\circ} \mathrm{C}$. Cities in this cluster experienced significant increase in June and end months, August and September (Figure 2). 


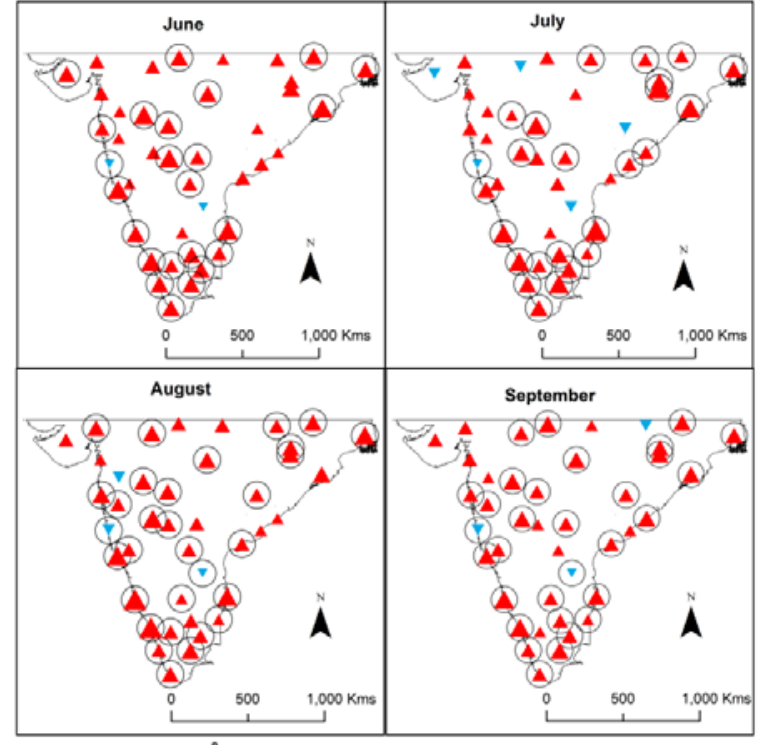

Absolute change in $\mathrm{HI}\left({ }^{\circ} \mathrm{C}\right)$

$\nabla<-1.0 \nabla-1.01-0.0 \wedge 0.01-1.0 \wedge 1.01-2.0 \wedge 2.01-3.0$

A $3.01 .4 .0 \boldsymbol{\Delta}>4.0$

Significant at $95 \%$

Fig. 2. Monthly trends in heat index

Cities situated in northeastern part of study area, namely Bhubaneswar, Kolkata, Ranchi, Jharsaguda and Samabalpur depict homogenous pattern of significant increase from July onwards till September, absolute increase at these cities was more than $2^{\circ} \mathrm{C}$ and thus formed highly vulnerable group (cluster 4) in accordance to rising heat stress. Highest absolute increase in this cluster was observed at Bhubaneswar (3.4 $\mathrm{C}$, June) followed by Kolkata (3.0 $\mathrm{C}$ August). Overall, absolute increase in this group was consistently above $2^{\circ} \mathrm{C}$.

Amongst all the clusters identified, cluster 5 registered highest significant absolute increase in heat stress. Over Chennai, $4^{\text {th }}$ largest metropolitan city of India, heat stress marked increase of $3^{\circ} \mathrm{C}$ to $4^{\circ} \mathrm{C}$ from June onwards till August, similar prominent increase was noticed over Mangalore and Kozhikode. Highest increase in this cluster was noticed during month of July followed by August (Figure 2). Contrary to pattern observed in cluster 5, cluster 6 depicted distinct pattern of meager to moderate increase in heat stress. It comprises of cities located in northern central part of study area (Figure 1). At Indore and Ambikapur during July and September respectively, decreasing trend was noticed. The absolute increase in this cluster ranges from $-0.4^{\circ} \mathrm{C}$ to $2.6^{\circ} \mathrm{C}$. Nagpur and Bhopal were the only stations which denoted increase of more than $1^{\circ} \mathrm{C}$ but less than $2.6^{\circ} \mathrm{C}$. Heat stress conditions have not aggravated much over these cities, they have remained more or less comfortable compared to cities in other clusters. The analysis identified seventh cluster over the southeastern part of India (Figure 1). Except Jagdalpur, other three cities (Vishakhapatnam, Machilipatnam and Kakinada) experience hot and humid climate pertaining to coastal location. At Kakinada and Vishakhapatnam significant increase in heat stress was observed in July, and in July and September respectively. While months of August and September were depicting significant increasing, trend over Machilipatnam and Jagdalpur. Highest increase of this cluster was observed at Vishakhapatnam in month of September $\left(2^{\circ} \mathrm{C}\right)$. Though heat stress shows increasing trend at these cities, the magnitude of increase was slow. The absolute range of heat stress in this cluster varies from $-0.4^{\circ} \mathrm{C}$ (July) at Jagdalpur to $2.1^{\circ} \mathrm{C}$ (September) over Vishakhapatnam. 


\subsection{Change point analysis}

The results of SQ-MK test used for detection of change point are represented in Table 1. In cluster 1 significant increase was observed at Aurangabad initiated after 1990s and cross positive significance level in early years of 2000 decade. Similarly increase over Mumbai was recent phenomenon in June and

\begin{tabular}{|c|c|c|c|c|}
\hline Stations & June & July & August & September \\
\hline Ahmedabad & & & 1977.2001 & \\
\hline Aurangabad & 1994 & 1992.2002 & 1995 & 1993 \\
\hline Mumbai & 2009 & & 1998 & 2009 \\
\hline \multicolumn{5}{|l|}{ Ozar } \\
\hline \multicolumn{5}{|l|}{ Pune } \\
\hline Rajkot & 1981,1990 & & & \\
\hline \multicolumn{5}{|l|}{ Ratnagiri } \\
\hline \multicolumn{5}{|l|}{ Surat } \\
\hline Bengaluru & & & 1994,2005 & 1997.2010 \\
\hline Cuddalore & 1993 & 2001 & 1986 & 1990 \\
\hline Kadapa & & & 2000 & 1997 \\
\hline Belagavi & & & 1992. 2000 & 1995 \\
\hline Hyderabad & 1992 & 2004 & & 1985.2000 \\
\hline Panaii & 2003 & & 1998 & 1994 \\
\hline Solapur & & 1995,2009 & 1995 & 1999. 2002 \\
\hline Kalaburagi & 1991 & & 2003 & \\
\hline Kurnool & 1992 & & 1995 & \\
\hline Parbhani & 2012 & & 2008 & 1984. 1986 \\
\hline Bhubaneswar & 2010 & 2005 & & 2000 \\
\hline Kolkata & 1995.2002 & 1997 & 1998 & 2010 \\
\hline Ranchi & 2011 & 2003 & 1993 & \\
\hline Jharsuguda & & 1975 & 1997 & 2004 \\
\hline Sambalpur & & 1999 & 1986 & 1987 \\
\hline Chennai & 2005 & 1990 & 1984 & 2008 \\
\hline Cochin & 2003 & 2001 & 2006 & 1997 \\
\hline Kozhikode & 1994 & 2000 & 1996 & 1998 \\
\hline Madurai & 1998 & 1996 & 2003 & 2004 \\
\hline Mangalore & 1991. 1996 & 2002 & 1995 & 1990 \\
\hline Thiruvananthapuram & 2005 & 2001 & 1997 & 1992 \\
\hline Tiruchirappalli & 1994. 2002 & 1998 & 1995 & \\
\hline Coimbatore & 1995 & 1998 & 2002 & \\
\hline Salem & 1986.2000 & 1997 & & 1990. 1993 \\
\hline \multicolumn{5}{|l|}{ Indore } \\
\hline Nagpur & 2006 & & 1988 & 1986 \\
\hline Bhopal & 1981,1992 & & & 2003 \\
\hline \multicolumn{5}{|l|}{ Jabalpur } \\
\hline Ambikapur & & 2010 & 19861995 & \\
\hline Kakinada & & 1996. 2006 & & \\
\hline Visakhapatnam & & 2002 & & 1998.2001 \\
\hline Machilipatnam & & & 2004 & 1995 \\
\hline Jagdalpur & & & 2010 & 19861995 \\
\hline
\end{tabular}

Table 1. Approximate year of change point in HI trends September, later to 2009. While at Ahmedabad and Rajkot, in August and June respectively, increasing trend was initiated in early 1980s. The city of Bengaluru, which has developed at faster pace following 1990s, showed rise in heat stress in late 1990s. Except Cuddalore in this cluster, for the month of August rising trend commenced in 1986. In cluster 3 , significant increase invariably started in the decade of 1990s (Table 1). Cluster 4 representing cities situated in northeastern part of study area depicted variable trend. Bhubaneswar showed increase after 2000 in all monsoon months except August, while at Sambalpur rise in heat stress begun after 1986 during end months of monsoon. Kolkata another important densely populated urban agglomeration portrayed significant increase later to 1995 . Cluster 5 , over southern tip of peninsular India showed highest significant absolute increase during the study period. For all

cities of this cluster, during all four months of monsoon season increasing trend commenced in late 1980s and prominently after 1990s (Table 1). At Chennai, largest metropolitan city within this cluster, in June and September increase was observed after 2005 and 2008 respectively. In August increase in heat stress started from 1984, while at July from 1990. Recent increase in heat stress was also observed at Cochin. Contradictory pattern of modest increase or decrease in heat stress was observed in cluster 6 . At Nagpur increase begun in year 2006 for the month of June, but in August and September increasing trend occurred early, that is from 1988 and 1986. Similar pattern was observed at Ambikapur in July and August (Table 1). The southeastern coastal cities of Kakinada, Vishakhapatnam and Machilipatnam depicted initiation of significant trend in late 1990s and early decade of 2000. 


\section{CONCLUSION}

Though burst of monsoon provides relief from scorching summer heat as air temperature decreases considerably, injection of moisture with arrival of monsoon augments sultriness in air. Thus combined effect of temperature and moisture create heat stress/ thermal discomfort conditions. The present study highlights this phenomenon as most of the urban stations selected depict increasing trend in HI values. The results of study shows that heat stress conditions are surely building over developing urban centers of India during SW monsoon season. Increasing trend is variable in terms of magnitude; cities of southern India are highly vulnerable with consistent increase of above $2^{\circ} \mathrm{C}$.

Similarly, populations dwelling in cities of southeastern part of study area are at higher risk of heat stress. The thermally comfortable conditions still exist in urban areas of north central India, but modest increase was peculiar during retreating monsoon season, Overall analysis shows that August and particularly September are the months highly vulnerable to heat stress. Thus, it was observed that heat stress conditions get worsen during retreating monsoon phase over most of the parts of central India, while during transition month of June heat stress conditions augment over cities of south India. The change point detection invites attention on the fact that, increasing trend in heat stress is recent phenomena at most of the stations and was initiated in decade of 1990s. India is in forefront to develop adaptive strategies for inevitable consequences of climate change. Effect of climate variability on human health cannot be ignored. The present study emphasizes on need of mitigation strategies and development of indigenous thermal discomfort indices for tropical region as population in these developing countries is highly susceptible to heat stress adversities.

\section{REFERENCES}

1. Ahmad I, Tang D, Wang T, et al (2015) Precipitation Trends over Time Using Mann-Kendall and Spearman 's rho Tests in Swat River Basin , Pakistan.

2. Anderson GB, Bell ML, Peng RD (2013) Review Methods to Calculate the Heat Index as an Exposure Metric in Environmental Health Research. 121:1111-1119.

3. Antonopoulos VZ, Papamichail DM, Mitsiou KA (2001) Statistical and trend analysis of water quality and quantity data for the Strymon River in Greece. 5:679692.

4. Arnfield AJ (2003) Two decades of urban climate research: A review of turbulence, exchanges of energy and water, and the urban heat island. Int $\mathrm{J}$ Climatol 23:1-26.

5. Brooke Anderson G, Bell ML, Peng RD (2013) Methods to calculate the heat index as an exposure metric in environmental health research. Environ Health Perspect 121:1111-1119. doi: 10.1289/ehp.1206273

6. Chattopadhyay S, Edwards DR (2016) Long-Term Trend Analysis of Precipitation and Air Temperature for Kentucky , United States. doi: 10.3390/cli4010010

7. Cormack RMRS (1971) A Reviw of Classification. J R Stat Soc 134:1-30. 
8. Dash SK, Jenamani RK, Kalsi SR, Panda SK (2007) Some evidence of climate change in twentieth-century India. Clim Change 85:299-321. doi: 10.1007/s10584007-9305-9

9. Gadgil A, Dhorde A (2005) Temperature trends in twentieth century at Pune, India. Atmos Environ 39:6550-6556. doi: 10.1016/j.atmosenv.2005.07.032

10. Glazer JL (2005) Management of heatstroke and heat exhaustion. Am Fam Physician 71:2133-2142.

11. Gong X, Richman M (1995) On the application of cluster analysis to growing season precipitation data in North America east of the Rockies.

12. Hirsch RM, Slack JR, Smith RA (1982) Techniques of trend analysis for monthly water quality data. Water Resour Res 18:107-121. doi: 10.1029/WR018i001p00107

13. Iheanacho I (2014) Can the USA National Weather Service Heat Index Substitute for Wet Bulb Globe Temperature for Heat Stress Exposure Assessment?

14. IPCC (2008) Climate change and water: IPCC Technical Paper VI.

15. Karpouzos DK, Kavalieratou S, Babajimopoulos C (2010) Trend Analysis of Precipitation Data in Pieria Region ( Greece ). 31-40.

16. Kleerekoper L, Van Esch M, Salcedo TB (2012) How to make a city climate-proof, addressing the urban heat island effect. Resour Conserv Recycl 64:30-38. doi: 10.1016/j.resconrec.2011.06.004

17. Mohan M, Gupta A, Bhati S (2014) A Modified Approach to Analyze Thermal Comfort Classification. Atmos Clim Sci 2014:7-19.

18. Partal T, Kahya E (2006) Trend analysis in Turkish precipitation data.

19. Richette P, Clerson P, Périssin L, et al (2013) Revisiting comorbidities in gout: a cluster analysis. Ann Rheum Dis 74:142-146. doi: 10.1136/annrheumdis-2013-203779

20. Robinson PJ (2001) On the definition of a heat wave. J Appl Meteorol 40:762-775. doi: 10.1175/1520-0450(2001)040<0762:otdoah>2.0.co;2

21. Rothfusz LP, Headquarters NSR (1990) The heat index equation (or, more than you ever wanted to know about heat index). Fort Worth, Texas Natl Ocean Atmos Adm Natl Weather Serv Off Meteorol 23-90.

22. Smoyer KE, Rainham DGC, Hewko JN (2000) Heat-stress-related mortality in five cities in Southern Ontario : 1980 - 1996. 190-197.

23. Steadman RG (1979) The Assessment of Sultriness. Part I: A Temperature-Humidity Index Based on Human Physiology and Clothing Science. J. Appl. Meteorol. 18:861-873.

24. Stocker T, Qin D, Plattner G, Tignor M (2013) IPCC, 2013: climate change 2013: the physical science basis. Contribution of working group I to the fifth assessment report of the intergovernmental panel.

25. Unger J (1999) Comparisons of urban and rural bioclimatological conditions in the case of a central-European city. Int J Biometeorol 43:139-144.

26. Zarenistanak M, Dhorde AG, Kripalani RH (2014) Trend analysis and change point detection of annual and seasonal precipitation and temperature series over southwest Iran. 281-295. 